\title{
Platelet Function Testing after Transcatheter Aortic Valve Implantation
}

\author{
Davide Capodanno ${ }^{1}$ Antonio Greco ${ }^{1}$ \\ ${ }^{1}$ CAST, A.O.U. “Policlinico-Vittorio Emanuele," Catania, Italy \\ Thromb Haemost 2018;118:1681-1685.
}

Transcatheter aortic valve implantation (TAVI) is the standard of care for patients with severe aortic stenosis who are inoperable, and a valid alternative to surgery for patients at high or intermediate surgical risk. ${ }^{1}$ Current candidates to TAVI are typically octogenarians, which makes their propensity to thrombus formation or bleeding higher at baseline compared with younger individuals. ${ }^{2}$ It is of no surprise that TAVI itself further contributes to increase the risk of ischaemic and haemorrhagic complications in this population. ${ }^{3}$

Despite numerous technical innovations over the years, cerebrovascular events are still detected in 4 to $6 \%$ of intermediate-risk patients at 30 days, typically as the consequence of procedural factors. ${ }^{4}$ Subsequently, the risk of cerebrovascular events peaks at 8 to $10 \%$ at 1 year and 10 to $12 \%$ at 2 years, with late events mostly explained by concurrent patient-related (e.g. atrial fibrillation) and valve-related (e.g. stent surface exposure, leaflet thrombosis) conditions. ${ }^{4}$ Leaflet thrombosis is an emerging concern of uncertain clinical significance, more frequently observed with transcatheter valves rather than surgical bioprostheses, which is more likely to resolve with anti-coagulants rather than anti-platelets. ${ }^{5,6}$

Bleeding in TAVI patients is approximately $31 \%$ at 5 years, with similar proportions of access-site and non-access siterelated events, and a well-known detrimental impact on prognosis. $^{7,8}$ Of non-access-site bleeding, approximately $40 \%$ of the episodes (mostly neurological and gastrointestinal) accrue beyond 30 days. ${ }^{4,8}$ The incidence and timing of bleeding and ischaemic complications after TAVI call into question the net benefit of using adjuvant anti-thrombotic therapies in this setting. Current guidelines from the European Society of Cardiology recommend clopidogrel in addition to aspirin for 3 to 6 months after TAVI in patients who are not candidates to oral anti-coagulation, followed by single anti-platelet therapy lifelong (class IIa). ${ }^{9}$ Patients at high risk of bleeding may be considered eligible upfront for antiplatelet monotherapy (class IIb). In the United States, joint guidelines from the American College of Cardiology and

Address for correspondence Davide Capodanno, MD, PhD, CAST, A.O.U. "Policlinico-Vittorio Emanuele," P.O. Rodolico, Ed. 8, Via Santa Sofia 78, Catania, Italy (e-mail: dcapodanno@gmail.com).

American Heart Association recommend dual-anti-platelet therapy (DAPT) for 6 months (class IIb). ${ }^{10}$ Therefore, antiplatelet therapy with aspirin and/or clopidogrel is the current anti-thrombotic standard for non-anti-coagulated patients undergoing TAVI.

Investigations from the field of percutaneous coronary intervention $(\mathrm{PCI})$ have consistently demonstrated some degree of inter-individual variability in the platelet response to clopidogrel, ${ }^{11}$ and high on-treatment platelet reactivity may have prognostic implications. ${ }^{12-15}$ Several platelet function assays (e.g., light transmission aggregometry, VerifyNow, multiple electrode aggregometry) allow distinguishing patients with on-clopidogrel high platelet reactivity (HPR) or low platelet reactivity (LPL) based on standardized cut-off values. ${ }^{16,17}$ PCI studies suggest that HPR and LPR denote a status of impaired or undue response to clopidogrel, and carry a higher risk of thrombosis and bleeding, respectively. ${ }^{11}$

Nonetheless, the impact of tailoring anti-platelet therapy based on platelet function profiles is controversial. In elderly patients from the ANTARCTIC study-a population that resembles but does not necessarily match the population of patients undergoing TAVI-platelet function monitoring with treatment adjustment did not improve the clinical outcomes of PCI. ${ }^{18}$ In the TAVI field, the association of platelet reactivity and clinical outcomes has been investigated in small studies correlating on-treatment LPR and bleeding $^{19-23}$ (- Table $\mathbf{1}$ ).

In this issue of Thrombosis and Haemostasis, Gross et al add to this evidence with another instructive investigation. ${ }^{24}$ The authors studied platelet reactivity by using the Multiplate analyzer ${ }^{25}$ in 136 consecutive TAVI patients on DAPT with aspirin plus a $\mathrm{P}^{2} \mathrm{Y}_{12}$ inhibitor (mostly clopidogrel). Bleedings were assessed according to the Valve Academic Research Consortium-2 (VARC-2) definition. ${ }^{26}$ At 30 days post-TAVI, there was a significant association between LPR and VARC-2 bleeding both in unadjusted (hazard ratio [HR], $2.10,95 \%$ confidence interval [CI], 1.17-3.79; $p=0.01$ ) and age-adjusted ( $\left.\mathrm{HR}_{\mathrm{adj}}, 2.06,95 \% \mathrm{Cl}, 1.14-3.71 ; p=0.02\right)$

(c) 2018 Georg Thieme Verlag KG Stuttgart · New York
DOI https://doi.org/ 10.1055/s-0038-1672215. ISSN 0340-6245. received

September 4, 2018

accepted

September 4, 2018 


\begin{tabular}{|c|c|c|c|c|c|c|c|c|c|c|c|c|c|c|c|}
\hline 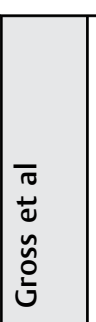 & $\stackrel{\infty}{\stackrel{\infty}{2}}$ & 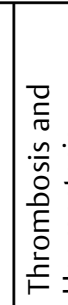 & $\frac{1}{2}$ & $\mid \begin{array}{l}\vec{D} \\
\infty \\
+ \\
\infty \\
\bar{\infty}\end{array}$ & & $\begin{array}{l}\frac{E}{5} \\
\frac{5}{m} \\
m\end{array}$ & $\Sigma$ & 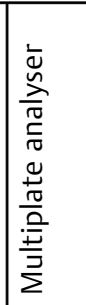 & 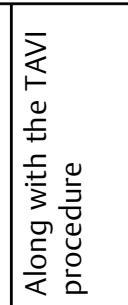 & 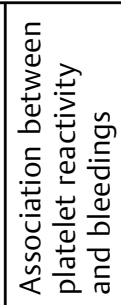 & $\begin{array}{l}0 \\
\check{0} \\
\text { ż }\end{array}$ & 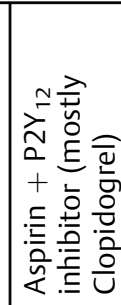 & $\frac{1}{3}$ & 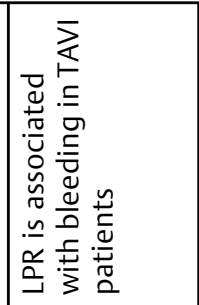 & 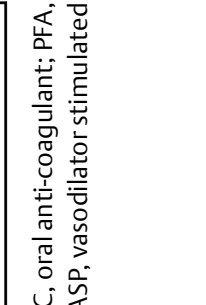 \\
\hline 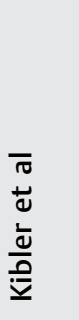 & $\stackrel{\infty}{\stackrel{\infty}{N}}$ & 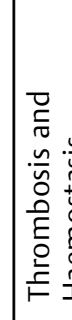 & $\frac{\sigma}{\pi}$ & 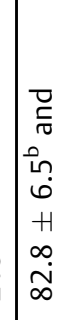 & $\frac{4}{2}$ & $\mathbb{z}$ & $\begin{array}{l}\widehat{\infty} \\
\infty \\
\infty \\
\infty \\
\infty \\
\infty\end{array}$ & $\begin{array}{l}8 \\
\frac{1}{\frac{1}{\frac{1}{2}}} \\
\frac{1}{2}\end{array}$ & 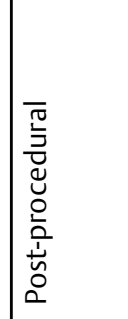 & 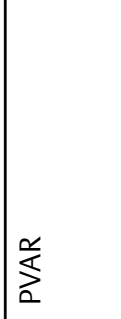 & 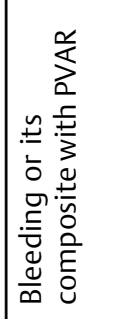 & 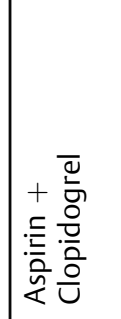 & 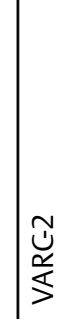 & 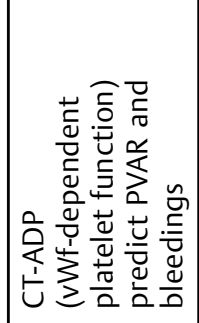 & 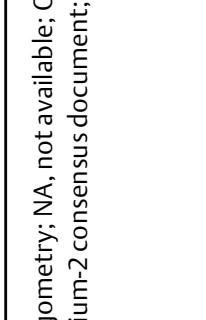 \\
\hline 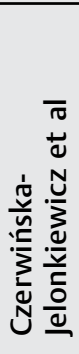 & 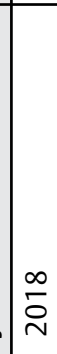 & 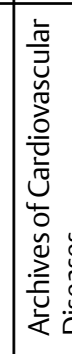 & 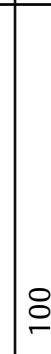 & $\begin{array}{l}0 \\
\frac{0}{\pi} \\
0 \\
0 \\
\sigma \\
\sigma \\
+1 \\
m \\
0 \\
0 \\
1\end{array}$ & & & 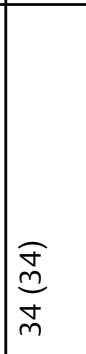 & 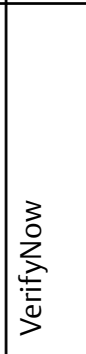 & 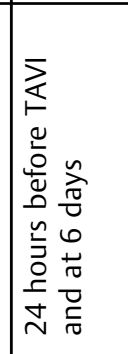 & 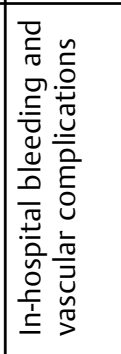 & $\Sigma$ & 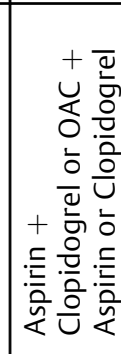 & 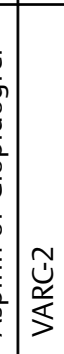 & 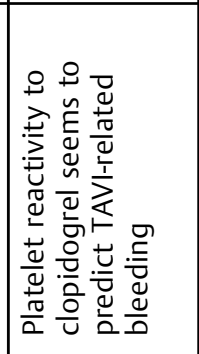 & 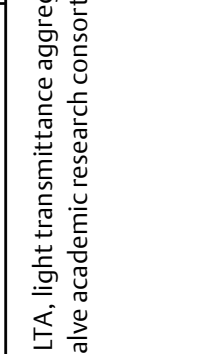 \\
\hline 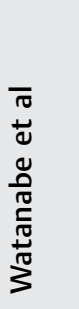 & 足 & 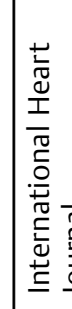 & $\approx$ & $\begin{array}{l}0 \\
\text { in } \\
+1 \\
\sim \\
\sim \\
\infty \\
\infty\end{array}$ & & 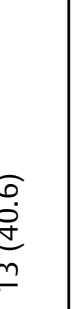 & $\mid \begin{array}{l}\widehat{\infty} \\
\infty \\
\stackrel{\infty}{c} \\
\sigma\end{array}$ & 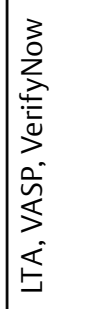 & 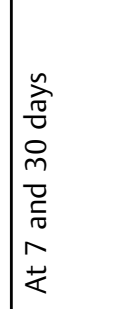 & 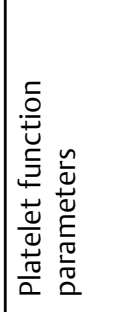 & 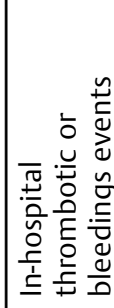 & 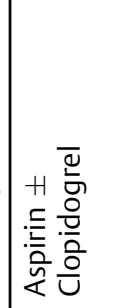 & 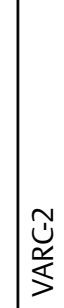 & 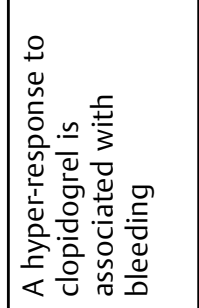 & 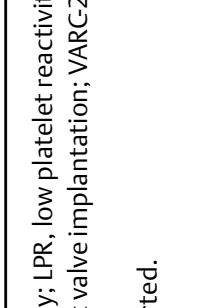 \\
\hline 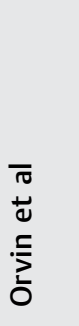 & i̊ & 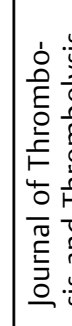 & 욜 & $\begin{array}{l}n \\
6 \\
H \\
H \\
\\
\infty \\
\infty\end{array}$ & $\frac{5}{4}$ & ¿ & 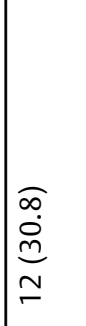 & 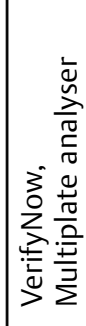 & 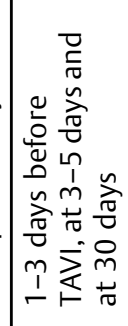 & 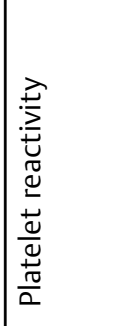 & $\begin{array}{l}0 \\
\text { Oे } \\
z\end{array}$ & 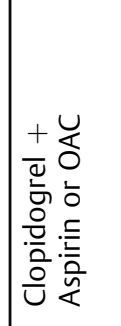 & \& & 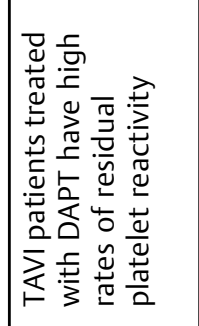 & 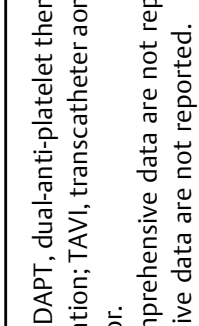 \\
\hline 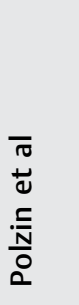 & $\stackrel{n}{\stackrel{2}{2}}$ & 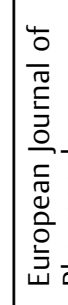 & ? & $\begin{array}{l}0 \\
+1 \\
\infty \\
\infty\end{array}$ & & $\begin{array}{l}2 \\
\substack{\infty \\
\sigma}\end{array}$ & $\begin{array}{l}\stackrel{\infty}{\infty} \\
\stackrel{2}{\sim}\end{array}$ & $\begin{array}{l}\Xi \\
\Xi \\
\overline{5} \\
\Sigma\end{array}$ & 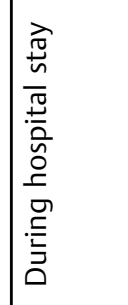 & 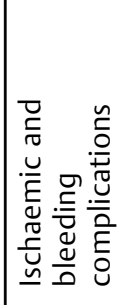 & $\begin{array}{l} \\
\check{0} \\
\check{z} \\
z\end{array}$ & 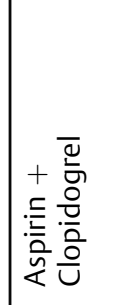 & 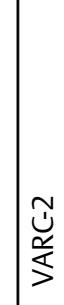 & 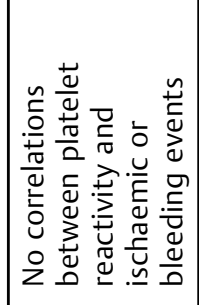 & 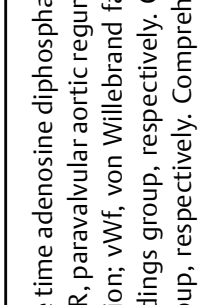 \\
\hline$\overline{\frac{\pi}{2}}$ & 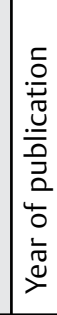 & - & 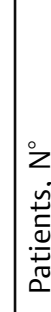 & 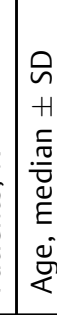 & & 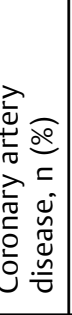 & 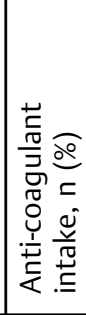 & 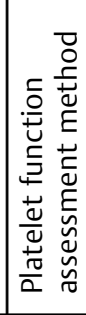 & 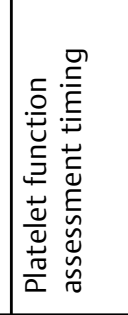 & 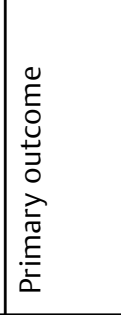 & 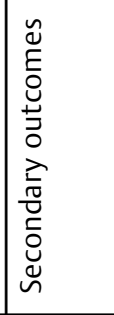 & 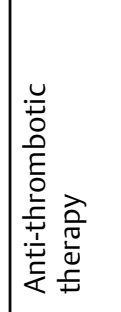 & 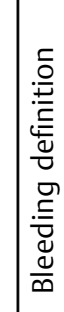 & 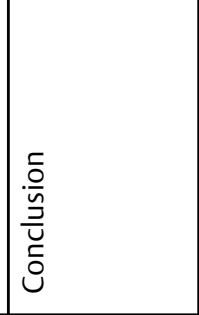 & 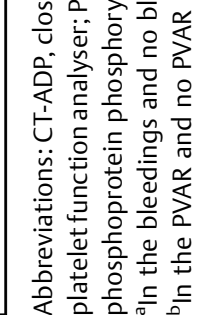 \\
\hline
\end{tabular}


analyses. In contrast, HPR was not significantly associated with the risk of ischaemic events. Although these results were obtained in a relatively small sample of patients, the study shows some admirable methodological aspects. Bleeding assessment was based on the broadly accepted VARC-2 definition, ${ }^{26}$ which is context-specific, and HPR and LPR were defined according to the cut-off values that were previously shown to link with adverse events in the PCI setting. ${ }^{27}$ In addition, the study population reflects contemporary TAVI practice in intermediate- to high-risk patients treated with either balloon-expandable or self-expandable bioprostheses, and the follow-up rate was complete.

Unfortunately, some caveats of this study should also be underlined. First, the conclusion that HPR was not associated with thrombotic events is undermined by the small number of ischaemic events at 30 days and resulting low power. Bleeding events were more frequent, which makes the inference about the association between LPR and haemorrhagic complications more statistically robust. Of interest, as eloquently shown by the Kaplan-Meier analysis, the higher propensity of LPR patients to bleed was mostly confined to the first 5 days from the procedure. Yet, the comparison between LPR and non-LPR patients was adjusted only by age and suffers from residual confounding, possibly including identifiable risk factors, because the result of univariate analyses for many variables of interest (e.g. demographic, clinical, procedural) was not reported. It would have been also valuable to know how many of the bleeding events occurring in LPR patients were life-threatening, major, or minor. The cut-off value of LPR identified for bleeding suffered from relatively low positive (53.6\%) and negative (75.6\%) predictive values, which is consistent with the multifactorial nature of bleeding. Other limitations include the availability of a single platelet function measurement, the lack of confirmation from other point-of-care assays and the inclusion of patients with different backgrounds of loading and maintenance $\mathrm{P}_{2} \mathrm{Y}_{12}$ inhibitor doses.

The net benefit of DAPT after TAVI has been recently questioned by a patient-level meta-analysis of three small randomized trials comparing DAPT with aspirin. ${ }^{28}$ Over a total of 421 patients, life-threatening VARC-2 bleeding at 30 days were significantly increased with DAPT ( $6.8 \%$ vs. $2.4 \%, p=0.036$ ), corresponding to a 2.68 -fold relative increase compared with aspirin. No differences in stroke and all-cause death were reported, but numbers were small. Further evidence on the merits of DAPT in the TAVI setting is expected from the on-going POPular-TAVI and CLOE trials. ${ }^{29}$ If DAPT will not be ultimately shown to be more beneficial than aspirin alone, speculating on HPR and LPR will become a sterile exercise in the TAVI scenario.

Another field of intense investigation is the role of anticoagulation in TAVI patients with no baseline indication for vitamin $\mathrm{K}$ antagonists or non-vitamin $\mathrm{K}$ antagonist oral anticoagulants. The joint American College of Cardiology and American Heart Association guideline for valvular heart disease affirms that a short term of anti-coagulation may be considered in these patients (class IIb), although it remains unclear if this regimen should be stacked on top of antiplatelet therapy. ${ }^{10}$ As expected, dual-pathway inhibition increases the risk of bleeding in the elderly population currently referred to TAVI. ${ }^{30}$ Also notably, the seminal GALILEO study, comparing a rivaroxaban-based with an antiplatelet-based strategy in TAVI patients, has been recently stopped due to an increase in safety events in the rivaroxaban arm (NCT02556203). Further insight on the comparison between anti-coagulants and anti-platelets in TAVI will come from the ATLANTIS trial of apixaban. ${ }^{31}$

Concomitant coronary artery disease is frequently discovered during the clinical work-up prior to TAVI and requires treatment in 20 to $40 \%$ of patients. ${ }^{32}$ Mostly based

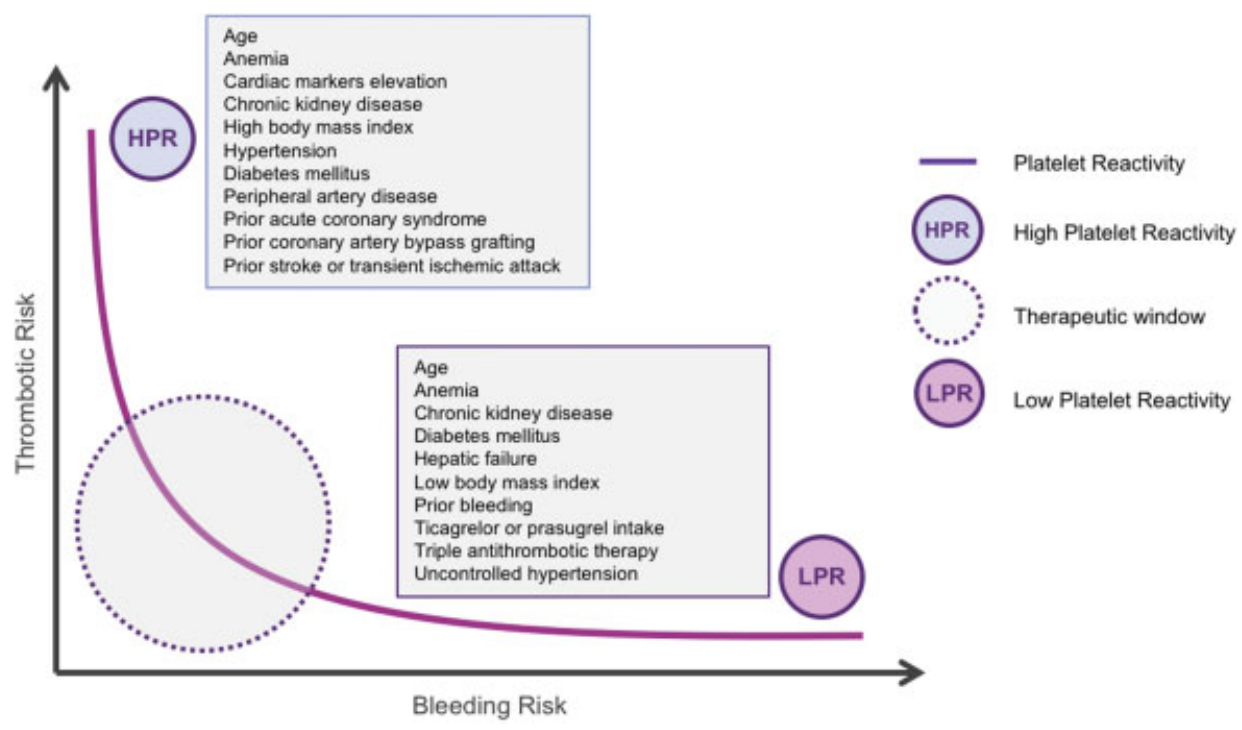

Fig. 1 Spectrum of potential platelet reactivity profiles in patients undergoing transcatheter aortic valve implantation (TAVI), ranging from high platelet reactivity (HPR) to low platelet reactivity (LPR). An area of "sweet spot" for the optimal use of anti-thrombotic medications is envisaged. Risk factors for HPR and LPR are proposed based on lessons from the field of percutaneous coronary intervention. ${ }^{11}$ 
on empiric considerations, guidance on the use of antithrombotic therapy after TAVI for these patients is given by two recent joint European consensus documents. ${ }^{33,34}$ TAVI patients who are already taking oral anti-coagulants and have recent $\mathrm{PCI}$ or an acute coronary syndrome should be treated similarly to patients receiving a stent without TAVI. Conversely, waiting for the results of on-going studies, patients undergoing TAVI without concomitant need for oral anti-coagulation should receive an anti-platelet regimen consisting of lifelong aspirin monotherapy or aspirin and clopidogrel for 3 to 6 months followed by aspirin monotherapy, depending on the bleeding risk, and concomitant treated or untreated coronary artery disease.

In conclusion, accruing evidences suggest that LPR may be one of the predisposing factors for bleeding in the TAVI setting, particularly early after the procedure. While this argument is not a call for guiding anti-platelet therapy by means of platelet function testing, it voices about the risk of anti-thrombotic over-treatment if one-size-fits-all strategies are implemented. Because the boundary between tailored therapy and under-treatment is equally thin, further evidence is needed to find the sweet spot of optimal pharmacotherapy in the TAVI setting (-Fig. 1). These investigations must take into account the ever-changing nature of TAVI in the context of improved safety and extension towards individuals at lower risk.

\section{Conflict of Interest}

None.

\section{References}

1 Baumgartner H, Falk V, Bax JJ, et al; ESC Scientific Document Group. 2017 ESC/EACTS Guidelines for the management of valvular heart disease. Eur Heart J 2017;38(36):2739-2791

2 Capodanno D, Angiolillo DJ. Antithrombotic therapy in the elderly. J Am Coll Cardiol 2010;56(21):1683-1692

3 Capodanno D, Angiolillo DJ. Antithrombotic therapy for prevention of cerebral thromboembolic events after transcatheter aortic valve replacement: evolving paradigms and ongoing directions. JACC Cardiovasc Interv 2017;10(13):1366-1369

4 Vranckx P, Windecker S, Welsh RC, Valgimigli M, Mehran R, Dangas G. Thrombo-embolic prevention after transcatheter aortic valve implantation. Eur Heart J 2017;38(45):3341-3350

5 Chakravarty T, Søndergaard L, Friedman J, et al; RESOLVE; SAVORY Investigators. Subclinical leaflet thrombosis in surgical and transcatheter bioprosthetic aortic valves: an observational study. Lancet 2017;389(10087):2383-2392

6 Capodanno D, Petronio AS, Prendergast B, et al. Standardized definitions of structural deterioration and valve failure in assessing long-term durability of transcatheter and surgical aortic bioprosthetic valves: a consensus statement from the European Association of Percutaneous Cardiovascular Interventions (EAPCI) endorsed by the European Society of Cardiology (ESC) and the European Association for Cardio-Thoracic Surgery (EACTS). Eur Heart J 2017;38(45): 3382-3390

7 Konigstein M, Ben-Assa E, Banai S, et al. Periprocedural bleeding, acute kidney injury, and long-term mortality after transcatheter aortic valve implantation. Can J Cardiol 2015;31(01):56-62

8 Piccolo R, Pilgrim T, Franzone A, et al. Frequency, timing, and impact of access-site and non-access-site bleeding on mortality among patients undergoing transcatheter aortic valve replacement. JACC Cardiovasc Interv 2017;10(14):1436-1446
9 Baumgartner H, Falk V, Bax JJ, et al; ESC Scientific Document Group. 2017 ESC/EACTS Guidelines for the management of valvular heart disease. Eur Heart J 2017;38(36):2739-2791

10 Nishimura RA, Otto CM, Bonow RO, et al. 2017 AHA/ACC focused update of the 2014 AHA/ACC Guideline for the management of patients with valvular heart disease: a report of the American College of Cardiology/American Heart Association Task Force on Clinical Practice Guidelines. Circulation 2017;135(25):e1159-e1195

11 Angiolillo DJ, Fernandez-Ortiz A, Bernardo E, et al. Variability in individual responsiveness to clopidogrel: clinical implications, management, and future perspectives. J Am Coll Cardiol 2007;49 (14):1505-1516

12 Bömicke T, Valina CM, Stratz C, Amann M, Neumann FJ, Hochholzer W. On-clopidogrel platelet reactivity as predictor for long-term clinical outcome in patients after planned discontinuation of clopidogrel. Thromb Haemost 2017;117(08): 1644-1650

13 Park Y, Tantry US, Koh J-S, et al. Novel role of platelet reactivity in adverse left ventricular remodelling after ST-segment elevation myocardial infarction: the REMODELING Trial. Thromb Haemost 2017; 117(05):911-922

14 Podda GM, Cattaneo M. High on treatment platelet reactivity as a risk factor for adverse left ventricular remodelling after STEMI. Thromb Haemost 2017;117(05):829

15 de Carvalho LP, Fong A, Troughton R, et al. Prognostic implications of dual platelet reactivity testing in acute coronary syndrome. Thromb Haemost 2018;118(02):415-426

16 Aradi D, Storey RF, Komócsi A, et al; Working Group on Thrombosis of the European Society of Cardiology. Expert position paper on the role of platelet function testing in patients undergoing percutaneous coronary intervention. Eur Heart J 2014;35(04): 209-215

17 Capodanno D, Angiolillo DJ. Platelet monitoring for PCI: which test is the one to choose? Hamostaseologie 2009;29(04):376-380

18 Cayla G, Cuisset T, Silvain J, et al; ANTARCTIC investigators. Platelet function monitoring to adjust antiplatelet therapy in elderly patients stented for an acute coronary syndrome (ANTARCTIC): an open-label, blinded-endpoint, randomised controlled superiority trial. Lancet 2016;388(10055):2015-2022

19 Polzin A, Schleicher M, Seidel H, et al. High on-treatment platelet reactivity in transcatheter aortic valve implantation patients. Eur J Pharmacol 2015;751:24-27

20 Orvin K, Eisen A, Perl L, et al. Platelet reactivity in patients undergoing transcatheter aortic valve implantation. J Thromb Thrombolysis 2016;42(01):11-18

21 Czerwińska-Jelonkiewicz K, Witkowski A, Dąbrowski M, Piotrowski W, Hryniewiecki T, Stępińska J. The role of platelet reactivity assessment in dual antiplatelet prophylaxis after transcatheter aortic valve implantation. Arch Cardiovasc Dis 2018;111 (04):233-245

22 Watanabe Y, Kozuma K, Ishikawa S, Hosogoe N, Isshiki T. Hyperresponse to clopidogrel in Japanese patients undergoing transcatheter aortic valve implantation. Int Heart J 2016;57(02): 190-197

23 Kibler M, Marchandot B, Messas N, et al. CT-ADP point-of-care assay predicts 30-day paravalvular aortic regurgitation and bleeding events following transcatheter aortic valve replacement. Thromb Haemost 2018;118(05):893-905

24 Gross L, Jochheim D, Nitschke T, et al. Platelet reactivity and early outcomes after transfemoral aortic valve implantation. Thromb Haemost 2018;118(10):1832-1838

25 Würtz M, Hvas AM, Christensen KH, Rubak P, Kristensen SD, Grove EL. Rapid evaluation of platelet function using the Multiplate ${ }^{\circledR}$ Analyzer. Platelets 2014;25(08):628-633

26 Kappetein AP, Head SJ, Généreux P, et al. Updated standardized endpoint definitions for transcatheter aortic valve implantation: the Valve Academic Research Consortium-2 consensus document. Eur Heart J 2012;33(19):2403-2418 
27 Aradi D, Kirtane A, Bonello L, et al. Bleeding and stent thrombosis on P2Y12-inhibitors: collaborative analysis on the role of platelet reactivity for risk stratification after percutaneous coronary intervention. Eur Heart J 2015;36(27):1762-1771

28 Maes F, Stabile E, Ussia GP, et al. Meta-analysis comparing single versus dual antiplatelet therapy following transcatheter aortic valve implantation. Am J Cardiol 2018;122(02):310-315

29 Nijenhuis VJ, Bennaghmouch N, Hassell M, et al. Rationale and design of POPular-TAVI: antiPlatelet therapy for patients undergoing transcatheter aortic valve implantation. Am Heart J 2016;173:77-85

30 Abdul-Jawad Altisent O, Durand E, Muñoz-García AJ, et al. Warfarin and antiplatelet therapy versus warfarin alone for treating patients with atrial fibrillation undergoing transcatheter aortic valve replacement. JACC Cardiovasc Interv 2016;9(16):1706-1717

31 Collet J-P, Berti S, Cequier A, et al. Oral anti-Xa anticoagulation after trans-aortic valve implantation for aortic stenosis: the randomized ATLANTIS trial. Am Heart J 2018;200:44-50

32 Barbanti M, Todaro D, Costa G, et al. Optimized screening of coronary artery disease with invasive coronary angiography and ad hoc percutaneous coronary intervention during transcatheter aortic valve replacement. Circ Cardiovasc Interv 2017;10(08):10

33 Lip GYH, Collet JP, Haude M, et al. Joint European consensus document on the management of antithrombotic therapy in atrial fibrillation patients presenting with acute coronary syndrome and/or undergoing percutaneous cardiovascular interventions: a joint consensus document of the Europ. Europace 2018 Jul 21. Doi: 10.1093/europace/euy174. [Epub ahead of print]

34 Lip GYH, Collet J-P, de Caterina R, et al. Antithrombotic therapy in atrial fibrillation associated with valvular heart disease: executive summary of a joint consensus document from the European Heart Rhythm Association (EHRA) and European Society of Cardiology Working Group on Thrombosis, Endorsed by the ESC Working Group on Valvular Heart Disease, Cardiac Arrhythmia Society of Southern Africa (CASSA), Heart Rhythm Society (HRS), Asia Pacific Heart Rhythm Society (APHRS), South African Heart (SA Heart) Association and Sociedad Latinoamericana de Estimulación Cardíaca y Electrofisiología (SOLEACE). Thromb Haemost 2017;117 (12):2215-2236 